Pediat. Radiol. 2, 69-72 (1974)

(C) by Springer-Verlag 1974

\title{
A Simple Technique for Eliminating Tracheal Buckling on Lateral Neck Roentgenograms
}

\author{
Paul E. Berger, Lawrence R. Kuhns, and Andrew K. Poznanski \\ Division of Pediatric Radiology, C. S. Mott Children's Hospital, The University of Michigan, \\ Ann Arbor, Michigan, USA
}

\begin{abstract}
Brief, gentle extrinsic pressure on the trachea at the level of the cricothyroid membrane during lateral roentgenography of the neck is suggested as a safe, simple, and
\end{abstract}

reliable means of evaluating the retrotracheal pre-cervical soft tissues in infants and children.

Key words: Trachea, technique, neck soft tissues.
Evaluation of the retrotracheal soft tissues in infants and children is difficult due to the variation in soft tissue thickness during respiration. It is our purpose to report a simple method for evaluation of the retrotracheal pre-cervical soft tissues. In 1930, Hay [4] noted that on the lateral roentgenogram of the neck in infants and children the trachea buckled forward during expiration. He regarded this buckling as normal and felt it was due to "crowding of the trachea during expiration", due to lax retropharyngeal tissues, and stressed the need to examine the neck in both phases of respiration. He noted that one might be misled into making a diagnosis of retropharyngeal abscess on a lateral roentgenogram of the neck if the film was obtained during the expiratory phase of respiration.

One approach to accurate determination of the soft tissues of the neck is fluoroscopy and cine roentgenography. Brenner [2] noted that the duration of minimal thickness of the vertebral soft tissues during inspiration lasted only 0.2 seconds in most cases and during expiration soft tissue thickness increased markedly. This explains why it is often difficult to obtain a good inspiratory film without buckling of the trachea in the infant or young child, Often, several lateral films of the neck are obtained and none is satisfactory.

\section{Present Tecbnique}

Our technique for evaluating the retrotracheal pre-cervical soft tissues consists of gentle extrinsic pressure on the trachea at the level of the cricothyroid membrane. The patient is positioned for a lateral neck roentgenogram. The firm thyroid cartilage is easily palpable and just below this level is the cricoid cartilage and cricothyroid membrane. This portion of the trachea is somewhat protected from collapse by the ring-shaped cricoid cartilage. The cricothyroid membrane is first gently compressed with the radiologist's index finger to make sure the trachea does not deviate laterally around a mass during compression. The examiner then wears a lead glove and applies very brief, gentle extrinsic pressure with the index finger (Fig. $1 \mathrm{a}$ and b), during the roentgen exposure, thus displacing the trachea posteriorly and straightering any tracheal buckling which may be present. Compression need only be brief and gentle and airway compromise should not occur. Children examined in this manner do not complain of any discomfort. This gentle compression eliminates the need to obtain the film at peak inspiration and eliminates normal forward tracheal buckling. It provides a readily reproducible measure of vertebral retrotracheal soft tissue thickness. Satisfactory compression may be obtained in either slight flexion or extension of the neck. Also, satisfactory films have been obtained during both inspiration and expiration.

The trachea will appear as a straight radiolucent structure with a smooth posterior margin. A mass in the retrotracheal area may indent the posterior wall of the trachea. There is often a normal indentation posteriorly at the level of $\mathrm{C}_{3}-\mathrm{C}_{4}$ which is due to the arytenoid cartialges and the transverse and oblique arytenoid muscles (Fig. 2). This should not be misinterpreted as a retrotracheal mass.

We have used this technique for two years without any complications. Extrinsic pressure in a patient with surgically proven laryngeal web has been performed without difficulty. It is possible that a soft cystic retrotracheal mass could be compressed and a false negative result obtained, but we have not encountered this. Masses which may 


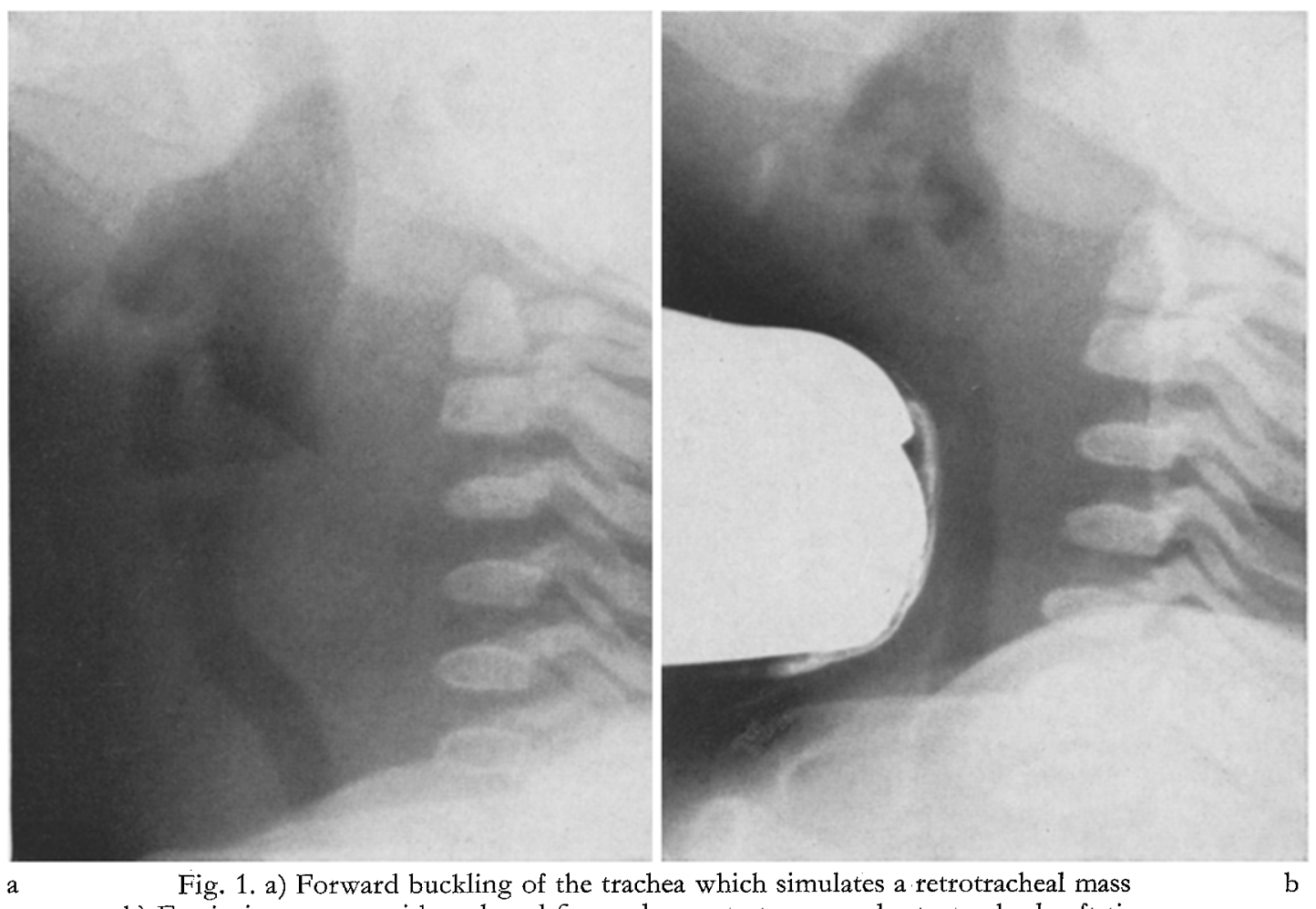

b) Extrinsic pressure with a gloved finger demonstrates normal retrotracheal soft tissues

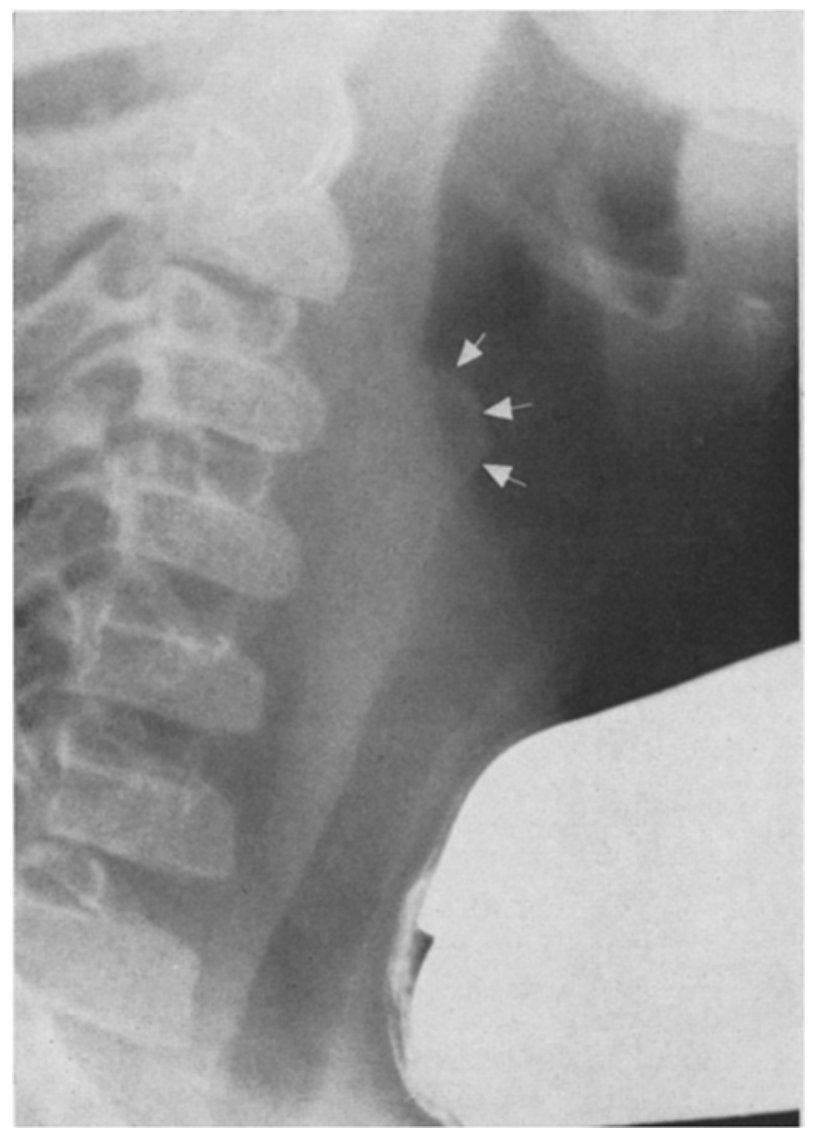

involve the retrotracheal soft tissues include retropharyngeal abscess [3], cystic hygroma [6], congenital goiter [5], hemangiopericytoma [1], and persistent cervical thymus [7].

Using this technique the pre-cervical soft tissues anterior to the $\mathrm{C}_{4}$ or $\mathrm{C}_{5}$ vertebral bodies were equal to or less than the antero-posterior diameter of the vertebral body in thirty-nine of forty children. This is in agreement with previous findings of Hay [4]. The single exception was a six week old boy whose vertebral body measured $8 \mathrm{~mm}$. and the anterior soft tissue was $9 \mathrm{~mm}$. thick. We feel this technique is simple, safe, and a reliable means of evaluating the retrotracheal pre-cervical soft tissues in infants and children.

\section{References}

1. Baden, M., Papageorgiou, A., Joshi, V. V., Stern, L.: Upper airway obstruction in a newborn secondary to hemangiopericytoma. Can. med. Assoc. J. 107, 1202-1204 (1972)

Fig. 2. Normal soft tissue density (arrows) due to the arytenoid cartilages and muscles which should not be misinter$\leftarrow \quad$ preted as a retrotracheal mass 
2. Brenner, G. H.: Variations in the depth of the cervical prevertebral tissues in normal infants studied by cinefluography. Amer. J. Roentgenol. 91, 573-577 (1964)

3. Greenwald, H. M., Messeloff, C. R.: Retropharyngeal abscess in infants and children. Amer. J. Med. Sci. 177, 767-777 (1929)

4. Hay, P. D., Jr.: In: The neck. Vol. IX of Annals of Roentgenology, pp. 22-28 and 82-93. Ed. J. T. Case. New York: P. B. Hoeber, Inc. 1930

5. Nagle, W. W., Hope, J. W., Bongiovanni, A. M.: Congenital goiter. Radiology 68, 526-533 (1957)
6. Stadler, H. E., Berman, J. K., Johnson, T. W.: Hygroma colli. J. Pediat. 41, 100-103 (1952)

7. Thompson, R. E., Love, W. G.: Persistent cervical thymus. Amer. J. Dis. Child. 124, 762-766 (1972)

Andrew K. Poznanski, M. D. Co-Director

Division of Pediatric Radiology

C. S. Mott Children's Hospital

Univ, of Mich. Medical Center

Ann Arbor, Michigan 48104

USA 